\title{
Encontros e (des)encontros no sistema família-escola
}

\author{
Tarcila Barboza Hidalgo Lima \\ Universidade Federal do Triângulo Mineiro - Uberaba - MG \\ Cibele Alves Chapadeiro \\ Universidade Federal do Triângulo Mineiro - Uberaba - MG
}

\begin{abstract}
Resumo
Este relato de pesquisa qualitativa tem como objetivo analisar sistemicamente a relação entre escola e famílias de crianças apontadas pelos professores como tendo problemas de aprendizagem, em uma escola da rede municipal da cidade de Hortolândia (SP). Participaram do estudo, por meio de entrevistas semiestruturadas, três professoras e cinco famílias de crianças apontadas como tendo dificuldades de aprendizagem. As entrevistas foram audiogravadas e transcritas. Foi realizada a análise de conteúdos e uma reflexão sistêmica sobre os dados obtidos a partir dos Encontros e (des)Encontros nas falas das professoras e das famílias entrevistadas. Verificou-se que professoras e famílias têm percepções diferentes que geram situações de acusações mútuas entre famílias e escola e que há falhas e dificuldades na comunicação entre os subsistemas. Os (des)Encontros fazem com que família e escola atuem de modo divergente, tornando a relação disfuncional.
\end{abstract}

Palavras-chave: aprendizagem; família; escola.

\section{Agreements and disagreements on the family-school system}

\begin{abstract}
This qualitative research report aimed to make a systemic analysis of the relationship between school and families of children identified by teachers as having learning problems, in a municipal school in the city of Hortolândia (SP). Three teachers and five families of children identified by teachers as having learning difficulties participated of this research through semi-structured interviews. The interviews were audio-recorded and transcribed. It was performed a content analysis in order to analyze systemically the data obtained from the agreements and disagreements in the speech of teachers and the families. It was found that teachers and families are distant of the systemic thinking, accusations in the familyschool relationship and there are communication failures between these subsystems. Disagreements make family and school acting divergently, making a dysfunctional relationship.
\end{abstract}

Keywords: Learning; family; school.

\section{Encuentros y (des)encuentros en el sistema familia-escuela}

\section{Resumen}

Este relato de investigación cualitativa tiene como objetivo analizar sistémicamente la relación entre escuela y familias de niños apuntadas por los profesores como teniendo problemas de aprendizaje, en una escuela de la red municipal de la ciudad de Hortolândia (SP). Participaron del estudio, por medio de entrevistas semiestructuradas, tres profesoras y cinco familias de niños señalados como teniendo dificultades de aprendizaje. Las entrevistas fueron audio-grabadas y transcritas. Se realizó el análisis de contenidos y una reflexión sistémica sobre los datos obtenidos a partir de los Encuentros y (des)Encuentros en las hablas de las profesoras y de las familias entrevistadas. Se percibió que profesoras y familias tienen percepciones distintas que generan situaciones de acusaciones mutuas entre familias y escuela y que hay fallas y dificultades en la comunicación entre los subsistemas. Los (des)Encuentros hacen con que familia y escuela actúen de modo divergente, volviendo la relación disfuncional.

Palabras clave: aprendizaje; familia; escuela. 


\section{Introdução}

Famílias têm se apresentado em diferentes configurações na sociedade: famílias multigeracionais, famílias reconstituídas ou recasadas, famílias de mãe ou pai solteiro, famílias apenas de casais, que coabitam ou não, famílias com pais homossexuais, famílias com filhos de inseminação artificial (Petzold, 1996; Stratton, 2003; Turner, \& West, 1998, citados por Oliveira, \& Marinho-Araújo, 2010; Polity, 2009), entre outras. Portanto, não é possível afirmar que existe uma definição de família aceita e adotada consensualmente pelos estudiosos da área, pelas instituições governamentais e pela sociedade (Oliveira, \& Marinho-Araújo, 2010). Diante dessa complexidade, o entendimento que se teve neste trabalho foi o da família como um sistema, assim como a escola, ambas compondo uma rede de relações complexas.

De acordo com Morin (2002 citado por Alves, \& Seminotti, 2006), sistema é uma unidade complexa, que se dá nas inter-relações entre suas partes e com o exterior; como o todo é maior do que a soma das partes, "o funcionamento do sistema não pode ser entendido a partir do funcionamento de um só indivíduo" (Andrada, 2005, p. 198). Entender a família como um sistema, segundo Alarcão (2000), significa ter uma visão global da sua estrutura (dimensão espacial) e do seu desenvolvimento (dimensão temporal), visão esta que também se pode ter do sistema escola. Alves e Seminotti (2006), ao discutirem o pensamento de Morin, afirmam que "não podemos compreender um sistema complexo segundo o pensamento reducionista, ou seja, compreender o todo somente a partir da separação, simplificação e redução das partes" (p. 117).

Assim, família é mais do que a soma de seus membros e, de igual modo, a escola vai além da soma de seus funcionários e alunos; para entendê-los "faz-se necessário procurar as relações e inter-retroações entre partes e todo, entre diferentes sistemas, considerando o contexto sócio-histórico onde estão situados e as relações de reciprocidade entre indivíduos e grupo, indivíduos e sociedade" (Alves, \& Seminotti, 2006, p. 117).

Minuchin (1982/1974 citado por Coelho, 2007), entende a família como um sistema complexo em processo de constante interação, que passa por transformações ao relacionar-se com outros sistemas, como o sistema escola. Minuchin, Colapinto e Minuchin (1998/1999) referem ainda que família é um sistema especial no qual a estabilidade e a mudança são organizadas. Família e escola estão sujeitas a transformações; o aluno deixou de ser um depositário de informações e passou a ser educado em um contexto criado pelo e no encontro das relações, em que o foco muda do exclusivamente individual para o inter-relacional (Polity, 2009). Esse novo modo de lidar com a educação, de enxergar o indivíduo em seu contexto e considerar as relações entre as partes se dá por meio do paradigma sistêmico.

O paradigma sistêmico deve levar à compreensão da dinâmica das relações funcionais ou disfuncionais, como por exemplo a dinâmica das crianças com problemas de aprendizagem. Andrada (2003) propõe que "o significado e o entendimento que o sistema escolar dá à dificuldade de aprendizagem podem ser transformados quando professores e pedagogos se colocam como sujeitos que também constroem e mantém o problema" (p. 172). O foco deixa de ser o aluno com suas dificuldades e passa a ser todo o sistema, considerando todas as causas e funções que o problema pode estar exercendo.

Para entender a função de um sintoma, de acordo com o pensamento sistêmico, é importante pontuar a característica reguladora dos sistemas. De acordo com Papp (1992), as partes estão constantemente mudando a fim de manter o sistema balanceado; assim, mantêm sua forma à medida que o padrão de ligação entre as partes se modifica. Para Coelho (2007), essa busca de equilíbrio pode acontecer tanto com questões internas como externas ao sistema, sendo que a mudança ocorrerá para garantir sua continuidade, fazendo, se necessário, com que se mobilizem outros padrões de relações entre as partes do sistema. A autora destaca ainda que, de acordo com a mudança, o sistema pode ter dificuldades em sua adaptação, podendo ocorrer um acúmulo de estresse pelo aumento da ansiedade e até mesmo produção de sintomas. O sintoma, então, é uma das formas de se equilibrar o sistema, e quando é inaceitável pela sociedade, acaba causando um estresse intolerável (Papp, 1992). Como o sintoma ocupa um papel estabilizador, lidar com ele exige que sejam trabalhados novos padrões de comportamento, modificando sequências rígidas e repetitivas, exigindo da escola e/ou da família que sejam feitas mudanças nas interações do sistema (Haley, 1979).

Para Satir (1980 citado por Andrada, 2003), o sintoma é um problema na comunicação. A educação das crianças com problemas de aprendizagem pode ser afetada pelo processo comunicacional circular escola-família-criança, especialmente quando se fala que a comunicação entre duas pessoas é sempre acompanhada da definição da relação destas (Watzlawick, Beavin, \& Jackson, 2007). Isso sinaliza o que Oliveira e Marinho-Araújo (2010) apontaram como fazendo parte da relação escola-família:

A comunicação entre escola e família passa pela intermediação da criança, sendo esta comunicação aparentemente de mão única, por haver pouco espaço institucional para a manifestação das famílias. A ação das famílias é limitada e determinada de acordo com os interesses da escola (p. 104).

O fracasso escolar é uma das facetas presentes no sistema educacional, sendo encontrada em todas as escolas: crianças com dificuldades de letramento, problemas comportamentais, dificuldades sensoriais e físicas (Rodrigues, 2010), apresentando como resultados a evasão escolar e a defasagem idade/série (Cohen, 2004). Rodrigues (2010) considera que as causas do insucesso na aprendizagem são diversas e que "o pensamento atual considera que necessidades especiais advêm não só de dentro da criança, mas resultam também de fatores externos, ambientais e familiares" (p. 148), necessidades que se referem às difi- 
culdades de aprendizagem dos alunos. Essa multiplicidade causal gera muitas expectativas em relação à educação por parte dos educadores e familiares, o que por sua vez gera culpa e conflitos na relação família-escola.

Comumente, há uma preocupação em se encontrar um culpado para o fracasso escolar: a escola culpa a falta de engajamento dos pais nas atividades escolares ou até mesmo a desorganização familiar, propagando a ideia de que o rendimento escolar está diretamente relacionado à dinâmica familiar (Oliveira, \& Marinho-Araújo, 2010).

Vê-se que a relação família-escola está permeada por um movimento de culpabilização e não de responsabilização compartilhada, além de estar marcada pela existência de uma forte atenção dirigida à instrumentalização dos pais para a ação educacional, por se acreditar que a participação da família é condição necessária para o sucesso escolar (Oliveira, \& Marinho-Araújo, 2010, p. 102).

Silveira e Wagner (2012) investigaram a interação família-escola em relação aos problemas de comportamento da criança. Das entrevistas realizadas com pais e professores, identificaram três eixos: o problema da criança do ponto de vista da família e da escola, as regras e os aspectos da dinâmica escolar presentes na relação escola-família, assim como as práticas educativas utilizadas, bem como as ideias que as sustentam. As autoras discutiram as continuidades e descontinuidades no processo de socialização das crianças. Uma descontinuidade estava relacionada à falta de conhecimento da escola e da família a respeito dos comportamentos das crianças e das práticas educativas. Um aspecto de continuidade abordado foi a comunicação entre os sistemas, em que todos os sujeitos relataram o uso do bilhete na interação família-escola, geralmente de caráter delator, pontuando, a partir de outros estudos, a importância de escola e família desenvolverem uma comunicação baseada na clareza e na confiança para a promoção de uma parceria.

Em revisão bibliográfica de artigos publicados entre 2002 e 2012, Dazzani, Cunha, Luttigards, Zucoloto e Santos (2014) verificaram que os estudos em que os profissionais lidam com estudantes com queixa escolar tendem a responsabilizar o aluno e a sua família pelo fracasso escolar.

Diante desse cenário e dos encontros e desencontros da família com a escola, Andrada (2005) aponta a importância do pensamento sistêmico dentro da escola, de modo que os problemas relacionados à educação não sejam mais vistos com causalidade linear, mas circular, passando o fracasso escolar a ser entendido a partir do funcionamento desses sistemas, escola e família, e a relação entre eles. Se essa visão for trabalhada, pode levar à responsabilização compartilhada como apontada por Oliveira e Marinho-Araújo (2010).

Ainda sobre a relação família-escola, Oliveira e Marinho-Araújo (2010) indicaram alguns caminhos para estudá-la, sendo um deles conhecer as concepções de professores a respeito das famílias de seus alunos e as concepções dos pais sobre a relação entre família e escola. Diante desta ideia e da realidade das novas configurações familiares, do paradigma sistêmico e dos problemas de aprendizagem dos alunos, surgiram alguns questionamentos: Quais sãos as crianças identificadas com problemas de aprendizagem? A que se atribuem essas dificuldades? Qual é a dinâmica que se estabelece em torno da criança com problemas de aprendizagem? Como tem sido a relação e a comunicação entre a escola e as famílias dessas crianças?

A partir das concepções dos professores e das famílias, a presente pesquisa teve como objetivo principal analisar sistemicamente a relação entre escola e famílias de crianças apontadas como tendo problemas de aprendizagem e com os seguintes objetivos específicos: identificar o que está sendo considerado como problemas de aprendizagem pela família e pela escola, verificar os fatores causais dos problemas de aprendizagem apontados pela escola e pela família, assim como verificar como tem sido a comunicação e a relação escola-família.

\section{Metodologia}

1. Trata-se de um estudo transversal, de caráter exploratório e qualitativo, baseado nos dados das entrevistas feitas com professoras de uma escola municipal de ensino fundamental de ciclo I de Hortolândia (SP) e com familiares de crianças apontadas pela escola como tendo problemas de aprendizagem.

2. O método qualitativo, de acordo com Minayo (2006).

3. É o que se aplica ao estudo da história, das relações, das representações, das crenças, das percepções e das opiniões, produtos das interpretações que os humanos fazem a respeito de como vivem, constroem seus artefatos e a si mesmos, sentem e pensam (p. 57).

4. Participaram desta pesquisa três professoras da escola e membros de cinco famílias de crianças apontadas pela instituição como tendo problemas de aprendizagem. Esse número de participantes foi suficiente para a saturação dos dados. A escolha dos professores foi feita pela diretora da escola, independentemente de gênero, sendo que o único critério era que deveriam lecionar para alunos que também participavam da classe de reforço escolar (grupo de apoio).

5. As professoras tinham idade entre 28 e 34 anos, formadas em Pedagogia e atuavam na docência, em média, há 11 anos. Ministravam aulas do minigrupo ao $5^{\circ}$ ano; entretanto nenhuma delas trabalhava com alfabetização $\left(1^{\circ}\right.$ ano do Ensino Fundamental).

6. As famílias foram indicadas pelas professoras sujeitos desta pesquisa. Os critérios para a escolha foram: famílias cujas crianças apresentassem problemas de aprendizagem e fizessem parte do grupo de reforço escolar oferecido pela escola. Os critérios para definir os problemas de aprendizagem deveriam ser da própria escola, a fim de se compreender o que esta entendia por problemas de aprendizagem. As crianças frequentavam do $2^{\circ}$ ao $5^{\circ}$ ano do ensino fundamental. $\mathrm{O}$ contato com as famílias se deu por 
telefone, convidando-as para participarem da pesquisa e, em seguida, para a entrevista na escola, em sala reservada ou em suas residências. Foram convidados para participar da entrevista os familiares que conviviam com a criança.

7. Professoras e familiares aceitaram participar voluntariamente da pesquisa por meio da assinatura do Termo de Consentimento Livre e Esclarecido. Apenas uma das famílias indicadas não compareceu à entrevista, mesmo inicialmente tendo aceito por telefone; neste caso, foi substituída por outra.

8. A Tabela 1 mostra a configuração de cada família participante, neste trabalho identificadas, respectivamente, como F1, F2, F3, F4 e F5, todas formadas coincidentemente por casal e filhos. Foram considerados apenas os que moravam na mesma casa que a criança identificada pela escola. A entrevista com a Família 4 (F4) teve participação de um dos filhos do casal, de 23 anos de idade, que não morava mais com a criança, por isso não foi identificado inicialmente como fazendo parte da F4.

9. Foram utilizados dois roteiros de entrevista semiestruturada, elaborados pelas pesquisadoras, sendo um utilizado para entrevista com as professoras e o outro com as famílias. Os roteiros contaram com os seguintes temas: caracterização do participante; caracterização da relação família-escola e caracterização da comunicação família-escola.

A partir da transcrição literal das entrevistas áudiogravadas, realizou-se Análise de Conteúdo baseada em
Bardin (1977/2011), utilizando-se análise temática, na qual foram elencadas algumas categorias temáticas em comum em todas as entrevistas, e de enunciação, a partir da qual foram analisadas as entrelinhas de cada entrevista. Realizou-se uma reflexão sob o referencial das teorias familiares sistêmicas, de modo a buscar as divergências e as convergências entre as concepções das professoras e dos familiares. A coleta dos dados, por meio das entrevistas, teve início após a aprovação pelo Comitê de Ética e Pesquisa (CEP) da Universidade Federal do Triângulo Mineiro (UFTM).

\section{Resultados}

A análise das falas dos entrevistados permitiu definir algumas categorias, isto é, foram reunidas falas semelhantes e diferentes das professoras entre si e dos familiares entre si. As categorias identificadas foram: identificação das crianças com problemas de aprendizagem; fatores relacionados aos problemas de aprendizagem; comunicação: meios, conteúdo e relação família-escola. Dentro das categorias, identificaram-se os Encontros e os (des)Encontros entre os relatos das professoras e dos familiares. Encontros foram entendidos como concepções convergentes e (des)Encontros, divergentes. Como as professoras sujeitos da pesquisa foram todas mulheres, foi utilizado o gênero feminino quando há referências a elas e gênero masculino aos professores da escola em geral.

Tabela 1. Caracterização das famílias participantes.

\begin{tabular}{|c|c|c|c|c|c|}
\hline Famílias & F1 & F2 & F3 & F4 & F5 \\
\hline Estado civil do casal & Casados & Casados & Casados & Amasiados & Casados \\
\hline Número de filhos & 3 & 1 & 3 & 3 & 3 \\
\hline Idade dos filhos & 3,9 e $10^{*}$ anos & $8^{*}$ anos & $8,8^{*}$ e 12 anos & $8^{*}, 11$ e 13 anos & $2,9^{*}$ e 15 anos \\
\hline Escolaridade da mãe & $\begin{array}{l}\text { Ensino Médio } \\
\text { completo }\end{array}$ & $\begin{array}{l}\text { Ensino Médio } \\
\text { completo }\end{array}$ & $\begin{array}{l}\text { Ensino Médio } \\
\text { incompleto }\end{array}$ & $\begin{array}{l}\text { Ensino } \\
\text { Fundamental } \\
\text { Incompleto }\end{array}$ & $\begin{array}{l}\text { Ensino } \\
\text { Fundamental } \\
\text { Incompleto }\end{array}$ \\
\hline Escolaridade do pai & $\begin{array}{l}\text { Ensino } \\
\text { Fundamental } \\
\text { Incompleto }\end{array}$ & $\begin{array}{l}\text { Ensino Médio } \\
\text { completo }\end{array}$ & $\begin{array}{l}\text { Ensino } \\
\text { Fundamental } \\
\text { Incompleto }\end{array}$ & $\begin{array}{l}\text { Ensino } \\
\text { Fundamental } \\
\text { Incompleto }\end{array}$ & $\begin{array}{c}\text { Ensino Médio } \\
\text { completo }\end{array}$ \\
\hline $\begin{array}{c}\text { Participante(s) da } \\
\text { entrevista }\end{array}$ & Mãe & Mãe & Mãe & $\begin{array}{c}\text { Pai, mãe e irmão } \\
\text { casado }\end{array}$ & Pai e mãe \\
\hline Local da entrevista & Escola & Escola & Escola & $\begin{array}{l}\text { Residência da } \\
\text { família }\end{array}$ & $\begin{array}{c}\text { Residência da } \\
\text { família }\end{array}$ \\
\hline
\end{tabular}

Nota: *Criança identificada pela escola como tendo problema de aprendizagem 


\section{Identificação das crianças com problemas de aprendizagem}

As professoras entrevistadas compreendiam que as crianças com problemas de aprendizagem eram aquelas com algum distúrbio psicológico passível de ser diagnosticado por um médico ou psicólogo. Deram ênfase às dificuldades relacionadas à leitura e à escrita para identificarem essas crianças. Apenas uma considerou que a criança poderia ter dificuldade em apenas um ou mais aspectos da aprendizagem, além das dificuldades na alfabetização.

Duas professoras definiram genericamente que 0 aluno com problemas de aprendizagem era aquele que não conseguia aprender quando lhe fosse ensinado, mesmo no seu nível de amadurecimento. Outra destacou que a indisciplina poderia estar associada aos problemas de aprendizagem e que deveria ser vista como um fator desencadeante ou como consequência do problema.

As famílias $(n=4)$ compreenderam que as crianças com problemas de aprendizagem eram aquelas com dificuldades de leitura e escrita, e também em outros aspectos, como em Matemática. As famílias também consideraram $(n=2)$ que as crianças com problemas de aprendizagem eram as crianças desatentas. Outras $(n=2)$ relataram que a escola apontava algum distúrbio em seus filhos; entretanto, não entendiam o que seria e tinham muitas dúvidas a respeito dos problemas de aprendizagem destes. Uma família relatou que não conseguia enxergar o progresso da criança da mesma forma que a escola, como um progresso suficiente para passá-la de série.

Uma das mães acreditava que o filho tinha algum distúrbio, entretanto o pai discordava, argumentando que problemas de aprendizagem eram diferentes de distúrbio. Ele entendia que o filho não tinha distúrbio, pois conseguia aprender outras coisas da prática cotidiana e que a falta de interesse da criança pelos estudos é o que fazia com que ela não tivesse um bom desempenho na escola. Outra mãe, do mesmo modo, se referiu ao desinteresse da criança, mas reconhecia as dificuldades que a própria criança tinha em entender e acompanhar o professor.

Os Encontros das concepções de professoras e famílias a respeito de quais eram as crianças com problemas de aprendizagem, conforme pode ser visualizado na Tabela 2, são: acreditar na presença de um distúrbio na criança, cujo diagnóstico compete a profissionais da área da saúde e identificar os aspectos da alfabetização, como leitura e escrita enquanto problema.

Os (des)Encontros ocorreram quando familiares, diferentemente das professoras, consideraram que as crianças com problemas de aprendizagem tinham outras dificuldades além da leitura e da escrita; ou quando as famílias não entendiam a dificuldade de seus filhos da mesma forma que as professoras, considerando também a desatenção e o desinteresse da criança pelos estudos. Também houve (des)Encontro entre a ideia que um pai e uma mãe tinham a respeito do que eram problemas de aprendizagem.

\section{Fatores relacionados aos problemas de aprendizagem}

Todas as professoras relacionaram os problemas de aprendizagem aos problemas familiares, citando como principais: o uso abusivo de álcool e de drogas pelos pais, agressão familiar, falhas no cuidado para com a criança e a coabitação de vários núcleos familiares no mesmo espaço. As professoras citaram a falta de incentivo dos pais para que os filhos estudassem, fosse porque estes não achavam a escola importante ou por eles mesmos não haverem estudado, por alguma razão. Além disso, todas as professoras apontaram as dificuldades da própria criança como relacionadas à dificuldade de aprendizagem. Duas professoras acreditavam que as dificuldades de aprendizagem estivessem relacionadas também a problemas na gestação.

As professoras $(n=2)$ ainda identificaram a progressão continuada como um dos fatores relacionados às dificuldades de aprendizagem, alegando que os alunos são promovidos para o próximo ano escolar sem aprenderem o

Tabela 2. Encontros e (des)Encontros da percepção na identificação da criança com problemas de aprendizagem

\section{Identificação da criança com problemas de aprendizagem}

\begin{tabular}{ll}
\hline Encontros & - Criança com algum distúrbio; \\
& - Criança com dificuldade para ler e escrever; \\
& - Criança cujo diagnóstico não compete aos professores e às famílias. \\
\hline & - Familiares consideraram que as crianças tinham dificuldades para aprender outras coisas além da leitura \\
(des)Encontros & e da escrita, enquanto as professoras consideravam apenas as dificuldades relacionadas à alfabetização; \\
& - Alguns pais não entendiam a dificuldade de seus filhos como apresentada pela professora; \\
& - Pais deram ênfase à desatenção e ao desinteresse dos filhos pelos estudos. \\
\hline
\end{tabular}


suficiente, tornando-os desmotivados, o que acaba resultando em discriminação pelos próprios colegas. Uma professora relatou dificuldade com salas de aula de alunos com níveis heterogêneos de aprendizagem. As famílias $(n=2)$ também identificaram o sistema educacional como contribuindo para as dificuldades das crianças, uma delas acrescentando a baixa qualidade do Ensino Público ou o despreparo dos professores para lidarem com os problemas de aprendizagem.

$\mathrm{Na}$ opinião das famílias $(n=4)$, a dificuldade de aprendizagem de seus filhos estava relacionada a alguma complicação na gestação, como hipertensão arterial e toxoplasmose, sendo que três dessas crianças nasceram prematuramente, aos sete meses de gestação. Acreditavam que a dificuldade estava na criança e era a razão $(n=3)$ do baixo desempenho escolar. Para duas delas as crianças tinham traumas psicológicos, um relacionado à mudança da criança de escola. Outras $(n=3)$ acreditavam que o desinteresse e a preguiça dos filhos estavam relacionados às suas dificuldades na escola.

Também relacionaram os problemas ao comportamento dos próprios pais. Duas famílias citaram as práticas educativas em que eles, pais, deixavam de colocar limites como um dos fatores que contribuíam; outra citou a influência das dificuldades de aprendizagem dos próprios pais, considerando até mesmo a possibilidade das dificuldades serem herdadas geneticamente; uma terceira mencionou a falta de tempo dos pais para acompanharem as atividades dos filhos.

Os Encontros entre professoras e famílias, conforme se observa na Tabela 3, estão em localizar na criança ou em sua gestação a origem das dificuldades de aprendizagem. Houve responsabilização do sistema educacional no que se refere à progressão continuada, lotação de salas com alunos em diferentes níveis de aprendizagem e qualidade do ensino público. A família também foi relacionada ao problema.

Referindo-se aos (des)Encontros, as professoras não se responsabilizaram pelos problemas de aprendizagem das crianças e não consideraram a possibilidade de suas próprias limitações; entretanto, os pais falaram do despreparo e da desqualificação dos professores. A maneira como as professoras relacionaram os problemas de aprendizagem às famílias diferiu de como as próprias famílias os relaciona- ram. Os pais foram os únicos que colocaram o desinteresse da criança pelos estudos como um dos fatores.

\section{Comunicação}

\section{A) Meios}

A comunicação das professoras com as famílias ocorria por meio de bilhetes ou pessoalmente, quando os pais iam até a escola. Elas se disponibilizavam a conversar com os pais durante o horário de trabalho e uma delas, fora dele também. Duas professoras telefonavam para os pais quando necessário. Uma delas deu uma ênfase maior ao uso de bilhetes, por meio de um caderno de recados, avisando-os do bilhete na hora da saída escolar.

Todas as famílias disseram que a escola se comunicava com elas por bilhetes e telefone, quando necessário. Apenas uma preferia conversar somente por bilhetes, as outras iam pessoalmente à escola em caso de necessidade. Outra relatou a ida da diretora da escola até sua casa para conversar sobre seu filho. A respeito dos meios de comunicação utilizados na relação família-escola, não houve (des)Encontros entre as falas das professoras e das famílias (Tabela 4).

\section{B) Conteúdo}

Segundo as professoras, a escola restringia a comunicação apenas ao que estava relacionado à educação, à disciplina, à aprendizagem e ao cotidiano escolar, sendo a família chamada apenas para resolver problemas. De acordo com todas as famílias entrevistadas, a comunicação não estava relacionada ao funcionamento da escola, mas era apenas uma conversa sobre os filhos que tinham problemas de aprendizagem. Duas famílias disseram que os professores as procuravam também quando estavam preocupados com a saúde da criança, com o acompanhamento psicológico ou com quem foi buscá-la na escola.

Também na subcategoria do conteúdo das comunicações entre família-escola, não houve (des)Encontro, conforme Tabela 5.

Tabela 3. Encontros e (des)Encontros da percepção a respeito dos fatores relacionados aos problemas de aprendizagem.

\section{Fatores relacionados aos problemas de aprendizagem}

\begin{tabular}{ll}
\hline & - Problemas na gestação; \\
& - Dificuldades da própria criança; \\
& - Sistema educacional como um todo; \\
Encontros & - Progressão Continuada foi mal vista por professoras e familiares; \\
& - Dificuldade de aprendizagem dos próprios pais; \\
& -Famílias responsabilizadas pelo problema de aprendizagem. \\
\hline & - Responsabilização dos professores pelas famílias; \\
(des)Encontros & - A responsabilização das famílias pelas professoras foi por motivos diferentes aos que os pais colocaram; \\
& - Pais entendem o desinteresse da criança como relacionado ao problema de aprendizagem. \\
\hline
\end{tabular}


Tabela 4. Encontros das percepções a respeito dos meios de comunicação

Meios de comunicação

\begin{tabular}{ll}
\hline & - Escola faz os comunicados através de bilhetes e telefonemas; \\
Encontros & - Pais conversam pessoalmente com os professores em horários disponibilizados para isso; \\
& - Pais também se comunicam com os professores através de bilhetes. \\
\hline
\end{tabular}

Tabela 5. Encontros das percepções a respeito dos conteúdos da comunicação

\section{Conteúdo da comunicação}

\section{C) Relação}

Conforme relato das professoras, as famílias iam à escola apenas quando eram chamadas e, ainda assim, muitas não iam. Muitas vezes, as famílias querem saber o resultado do ensino ao final do ano, mas ficam distantes do processo, não realizando contato e não participando das reuniões ao longo do ano, segundo uma entrevistada. Já outra disse que a família não se sente atraída pela escola e que não participa dos eventos.

Todas as professoras estavam insatisfeitas com a relação escola-família. O principal motivo apontado era a não participação dos pais nas atividades escolares. Uma professora relatou que a comunicação não precisaria ser apenas em torno da indisciplina ou das dificuldades da criança se os pais participassem mais dos eventos escolares.

Duas professoras percebiam a relação entre a família e a escola como uma relação de acusação e crítica mútua, uma relação forçada $(n=1)$, obrigada, e que havia poucas oportunidades para participação dos pais na escola. Ressaltou, ainda, que o projeto de visitação que havia na prefeitura era importante para os professores conhecerem os pais dos alunos. Os professores que desejassem participar desse projeto iam à casa de seus alunos para ter um maior contato com o aluno e sua família.

Outra professora pontuou que uma das dificuldades de comunicação relacionada às crianças com problemas de aprendizagem estava na falta de contato entre os professores regulares e professores de recursos, que eram os que trabalhavam com alunos de inclusão, a fim de realizar trabalho integrado.

Todas as famílias entrevistadas disseram ir à escola sempre que eram convocadas pelos professores. Uma mãe ia apenas nessas convocações por estar cansada de ouvir as mesmas coisas a respeito das dificuldades de seu filho nas reuniões bimestrais. Já outra família justificou a não participação pelo horário que coincidia com o do trabalho. Apenas uma das famílias gostava de participar dos eventos promovi- dos pela escola e referiu-se, junto com outra entrevistada, à pequena participação dos pais.

Duas famílias citaram o projeto de visitação dos professores. Uma o considerava muito importante e disse que a filha gostava do contato. Já outra sentia que os professores queriam investigar causas para a dificuldade de aprendizagem da criança, culpabilizando a família.

Além de falar sobre a comunicação com a escola, uma das famílias relatou que havia problemas de comunicação da criança em casa, pois esta apresentava muita dificuldade para entender o que os pais diziam.

As famílias $(n=4)$ disseram que o encontro com os professores era sempre para falarem sobre as dificuldades dos filhos, e que o contato era mais frequente quando a dificuldade da criança era mais grave. Apesar disso, algumas famílias $(n=3)$ disseram estar satisfeitas com a relação e o tipo de contato que tinham com a escola, uma justificando que a escola fazia o que estava ao seu alcance e outra com os resultados que obtinha a partir da comunicação. Outra ainda avaliou os encontros como insuficientes, por isso estava insatisfeita com o relacionamento com a escola. Ainda outra família revelou insatisfação com a comunicação, mas satisfação com o relacionamento que tinha com a diretora e professores.

Os Encontros da relação família-escola, conforme a Tabela 6, diziam respeito a compreender que a relação escola-família ocorria em torno dos problemas de aprendizagem e que a maioria dos pais não participava dos eventos da escola.

Os (des)Encontros apareceram quando as professoras visavam apenas os pais que não participavam das atividades na escola, sendo que havia uma minoria que participava e que não ia à escola apenas quando chamada. Outro (des)Encontro diz respeito às professoras se mostrarem insatisfeitas com o contato que tinham com as famílias, devido ao não envolvimento dos pais; quatro famílias se consideraram satisfeitas com a relação. Houve (des)Encontro também em relação ao projeto de visitação, pois tinham visões divergentes a respeito de sua importância. 
Tabela 6. Encontros e (des)Encontros das percepções a respeito da relação família-escola.

\section{Relação família-escola}

- A relação família-escola ocorria em torno do problema de aprendizagem;

\section{Encontros}

- Maioria dos pais não participava dos eventos na escola.

- Nem todas as famílias de crianças com problemas de aprendizagem vão à escola apenas quando são chamadas;

(des)Encontros $\quad$ - Há uma minoria de pais que participam, professores visavam os que não participam;

- Professoras não estão satisfeitas com o contato escola-família, familiares estão;

- Projeto de visitação.

\section{Discussão}

As categorias Identificação das crianças com problemas de aprendizagem, Fatores relacionados aos problemas de aprendizagem e Comunicação permitiram verificar que a relação entre família e escola está permeada por Encontros e (des)Encontros que ora contribuem para a funcionalidade da relação, ora não.

Os Encontros referentes à categoria Identificação das crianças com problemas de aprendizagem indicaram que professoras e familiares percebiam as crianças com problemas de aprendizagem como tendo algum distúrbio. Entretanto, a forma diferente como cada um compreendia o distúrbio era o que marcavam os (des)Encontros, pois professoras e familiares tinham condutas diferentes ao lidarem com os problemas da criança.

As escolas da cidade de Hortolândia não contam com o trabalho de Psicólogos na área da Educação e um dos papéis destes profissionais, apontado por Andrada (2005), é o de trabalhar junto à equipe pedagógica, criando espaços para discussão sobre novas formas de perceber os problemas de aprendizagem, de modo a minimizar a possibilidade de estigmatizar os alunos com dificuldades, inclusive, alinhar com os pais a visão a respeito das dificuldades das crianças.

As professoras também apontaram os problemas de aprendizagem como distúrbios a partir de um diagnóstico médico ou psicológico. Os professores geralmente recebem o diagnóstico sem apoio e orientações necessárias para a conduta que podem ter em sala de aula. A atuação da Psicologia na escola poderia minimizar esse distanciamento entre o problema e a prática, intermediando os posicionamentos diagnósticos dos profissionais de saúde com a prática escolar, profissionais estes que estão distantes da realidade escolar.

$\mathrm{Na}$ categoria Fatores relacionados aos problemas de aprendizagem, os problemas de aprendizagem foram relacionados às dificuldades da criança, do sistema educacional e da família, o que já aponta quais foram os principais (des) Encontros: a responsabilização dos professores pelas famílias e a responsabilização das famílias, pelas professoras e familiares, de modos diferentes. Esses (des)Encontros leva- ram a acusações e cobranças uns dos outros, assim como Oliveira e Marinho Araújo (2010) apontaram em seu trabalho ao discorrerem sobre a culpabilização que marca a relação família-escola. As professoras entrevistadas perceberam a relação de acusação mútua existente nessa relação, mas o que não se davam conta era que elas mesmas responsabilizaram as famílias, as crianças e o sistema educacional, de modo a não considerarem suas próprias limitações pessoais e profissionais ao lidarem com as dificuldades de aprendizagem de seus alunos. Assim como Andrada (2003) afirma, para haver mudança no trabalho com esses alunos é preciso que os educadores se coloquem como os sujeitos que também estão construindo e mantendo o problema.

No que se refere à responsabilização da criança, professoras consideraram as dificuldades e características das crianças ao falarem do não aprender, mas não consideram suas múltiplas potencialidades. Valorizaram as habilidades para escrita e leitura, descartando outras habilidades cognitivas como a criatividade, o desenhar e o raciocínio lógico. Quanto às crianças já alfabetizadas, mas com dificuldades em outras áreas, como na Matemática, ficavam sem um reforço escolar. Quando professores e famílias buscavam um diagnóstico para a criança, poderia ser mais uma tentativa de se olharem como distantes do sintoma, e responsabilizando-a por um possível transtorno.

Houve responsabilização do sistema educacional, em que a maioria das professoras e familiares relacionou a progressão continuada aos problemas de aprendizagem. De acordo com a proposta de progressão continuada nas escolas do Estado de São Paulo, o aluno deixa de ser aprovado ou reprovado no ano escolar e as aprendizagens diferenciais e o desenvolvimento global passam a ser trabalhados em ciclos (Neves, \& Boruchovitch, 2004). A perspectiva reducionista e linear com a qual as professoras percebiam e encaravam os problemas de aprendizagem provavelmente dificultava o desenvolvimento global do aluno. Estudos que relacionem o pensamento sistêmico ao regime de progressão continuada precisam ser realizados.

Entender os problemas de aprendizagem a partir do referencial sistêmico é compreender o sintoma em suas múl- 
tiplas facetas, fazendo-o interagir com todos os sistemas e subsistemas, no caso, o familiar, escolar e educacional. É deixar de compreender os problemas de aprendizagem a partir das partes que compõem o sistema e passar a entendê-los a partir da relação entre essas partes, como resultados de processos de interação com o ambiente (Del Prette, Paiva, \& Del Prette, 2005). É deixar de enxergar uma causalidade linear que gera culpa e enxergar com a visão de circularidade que subentende uma responsabilização compartilhada.

Também constituíram (des)Encontros nesta categoria o fato de as famílias pontuarem suas limitações ao lidar com as dificuldades dos filhos por também terem dificuldades para aprender, por não se envolverem de forma firme na educação dos filhos e por não terem tempo para acompanhá-los nas atividades escolares, justificando assim sua não participação nas atividades da escola. Essas pontuações lineares foram percebidas também quando as professoras se queixaram da baixa participação da família nas atividades promovidas pela escola e, por sua vez, a família se queixava dessas atividades, pontuando o problema de forma linear, embora haja um continuum na relação. Uma culpa a outra por iniciar e alimentar o problema na relação, mas tanto família como escola são igualmente responsáveis pela construção da relação entre elas. Além disso, a relação da escola com as famílias se concentrava em torno dos problemas das crianças, como se o sintoma estivesse sustentando essa relação. Conforme Haley (1979), quando o sintoma ocupa um papel estabilizador no sistema, exige-se mudança das sequências rígidas e repetitivas e dos padrões de comportamento para lidar com tal sintoma.

A relação entre a escola e a família estava comprometida não apenas pelo entendimento linear do problema, mas pela comunicação disfuncional. Na categoria Comunicação, os Encontros verificados na concepção que professoras e familiares tinham a respeito dos meios de comunicação mostram que as vias utilizadas pela escola e pelos familiares, fosse por meio de bilhetes, telefonemas ou pessoalmente, eram funcionais e permitiam uma comunicação bastante acessível a ambos, assim como em Silveira e Wagner (2012). Já os Encontros apresentados na subcategoria relativa ao conteúdo da comunicação, de que o contato entre família e escola se dava apenas em torno da educação, estão relacionados aos conflitos apresentados na subcategoria referente à percepção da relação família-escola, onde esta relação é vista como obrigada e alguns pais não participavam de reuniões por acharem-nas repetitivas, girando apenas em torno dos problemas dos filhos.

Professoras e familiares desconsideraram as falhas de comunicação ao descreverem os fatores que consideravam relacionados aos problemas de aprendizagem. Entretanto, verificaram-se falhas na comunicação em vários subsistemas: professor-família, professor-professor, professor-direção, professor-aluno, família-aluno, família-profissionais de saúde.

Apesar de ter havido apenas Encontros entre as falas das professoras e das famílias na subcategoria Conteúdo da comunicação, essa convergência de opiniões não significa funcionalidade. Famílias e professoras concordaram que há problemas na comunicação. Faltam estratégias adequadas para que a comunicação entre os sistemas seja funcional. Quanto aos meios de comunicação entre a escola e as famílias, eles apresentaram-se funcionais e as professoras se mostravam disponíveis para a comunicação com os pais. $O$ projeto de visitação dos professores da prefeitura de Hortolândia (SP) às casas dos alunos foi mencionado em algumas entrevistas, mas com (des)Encontros a respeito de sua importância no sistema. Esse projeto parece ser um veículo importante para a relação e a comunicação entre os sistemas, mas deve haver um entendimento acerca de como realizá-lo.

A relação que os professores tinham com os pais dos alunos mostrou-se como uma potencialidade quando não se tratava de problemas de aprendizagem, com meios de comunicação favoráveis. Quando o assunto é a dificuldade de aprendizagem dos alunos, faltam aos professores modelos que possibilitem a integração família-escola (Silveira, \& Wagner, 2012).

\section{Considerações finais}

Por meio da análise sistêmica da relação entre escola e famílias de crianças apontadas como tendo problemas de aprendizagem foi possível verificar que as professoras e os familiares lidavam com o problema de forma linear, isto é, uma relação de causalidade e não de interação entre eles, o que gerava acusações na relação família-escola. Uma visão sistêmica pode contribuir para que haja uma responsabilização compartilhada entre as partes do sistema, de modo a reorganizarem as estratégias com os alunos com problemas de aprendizagem e tornando a comunicação família-escola funcional. Os (des)Encontros no entendimento dos problemas de aprendizagem pela família e pela escola levam a posicionamentos divergentes. Essa reorganização da responsabilização poderá aliviar as tensões na relação entre os sistemas e favorecer o trabalho com os alunos.

As escolas, incluindo esta participante da pesquisa, poderão se beneficiar com profissionais da área da Educação que trabalhem a funcionalidade do sistema família-escola. Promover um espaço de diálogo na escola em que alunos, professores e famílias possam refletir sobre a forma como estão lidando com as situações cotidianas é um passo importante para o sistema família-escola trabalhar suas relações. Andrada (2005) aponta essa articulação como um dos papéis do Psicólogo Escolar.

O Psicólogo Escolar pode facilitar a relação entre a Saúde e Educação, dando suporte e capacitando os educadores a respeito das condutas necessárias diante de transtornos ou dificuldades que o aluno tenha.

O olhar sistêmico sobre a relação família-escola beneficia o ensino dos alunos com dificuldades na aprendizagem ou pode até conseguir evitá-las, pois existirão melhores condições de aprendizado e desenvolvimento da criança quando família e escola mantiverem boas relações (Polonia, \& Dessen, 2005). 
Há necessidade de pesquisas que investiguem mais sobre a relação entre Educação e Saúde e sobre o preparo dos profissionais para lidar com situações que permeiam ambas as áreas. Sugerem-se, também, pesquisas relacionando o regime de progressão continuada ao pensamento sistêmico, assim como estudos a respeito da contribuição da visão sistêmica no cumprimento das políticas públicas de educação, assim como os que investiguem o conhecimento das famílias a respeito dos problemas de aprendizagem e dos possíveis diagnósticos de transtornos relacionados ao processo de aprendizagem.

\section{Referências}

Alarcão, M. (2000). (des)Equilibrios familiares. Coimbra: Quarteto Editora.

Alves, M. C., \& Seminotti, N. (2006). O pequeno grupo e o paradigma da complexidade de Edgar Morin. Psicologia USP, 17(2), 113-133.

Andrada, E. G. C. (2003). Família, escola e a dificuldade de aprendizagem: intervindo sistemicamente. Psicologia escolar e educacional, 7(2), 171-178.

Andrada, E. G. C. (2005). Novos paradigmas na prática do psicólogo escolar. Psicologia: reflexão e crítica, 18(2), 196-199.

Bardin, L. (2011). Análise de conteúdo (L. A. Reto, \& A. Pinheiro, Trad.). São Paulo: Edições 70. (Trabalho original publicado em 1977).

Coelho, V. S. (2007). Aspectos estruturais do sistema familiar. Em J. G. Aun, M. J. E. Vasconcellos, \& V. S. Coelho (Orgs.), Atendimento sistêmico de famílias e redes sociais: o processo de atendimento sistêmico (Vol. 2, pp. 434-456). Belo Horizonte: Ophicina de Arte \& Prosa.

Cohen, R. H. (2004). O traumático encontro com os outros da educação: a família, a escola e o Estado. Psicologia em revista, 10(16), 256-269.

Dazzani, M. V. M., Cunha, E. O., Luttigards, P. M., Zucoloto, P. C. S. V., \& Santos, G. L. (2014). Queixa escolar: uma revisão crítica da produção científica nacional. Psicologia Escolar e Educacional, 18(3), 421-428.
Del Prette, Z. A. P., Paiva, M. L. M. F., \& Del Prette, A. (2005). Contribuições do referencial das habilidades sociais para uma abordagem sistêmica na compreensão do processo de ensinoaprendizagem. Interações, 10(20), 57-72.

Haley, J. (1979). Psicoterapia familiar. Belo Horizonte: Interlivros.

Neves, E. R., \& Boruchovith, E. (2004). A motivação de alunos no contexto de progressão continuada. Psicologia: teoria e pesquisa, 20(1), 77-85.

Minayo, M. C. S. (Org.). (2006). O desafio do conhecimento: pesquisa qualitativa em saúde (9a ed.). São Paulo: Editora Hucitec.

Minuchin, P., Colapinto, J., \& Minuchin, S. (1999). Trabalhando com familias pobres. Porto Alegre: Artes Médicas. (Trabalho original publicado em 1998).

Oliveira, C. B. E., \& Marinho-Araújo, C. M. (2010). A relação família-escola: intersecções e desafios. Estudos de Psicologia, 27(1), 99-108.

Papp, P. (1992). O dilema da mudança. Em P. Papp. Mudança: uma abordagem prática à terapia sistêmica da família (pp. 21-29). Porto Alegre: Artes Médicas.

Polity, E. (2009). Terapia familiar e educação: conversações que ampliam. Em L. C. Osório, \& M. E. P. Valle (Orgs.), Manual de terapia familiar (pp. 208-217). Porto Alegre: Artes Médicas.

Polonia, A. C., \& Dessen, M. A. (2005). Em busca de uma compreensão das relações entre família e escola. Psicologia Escolar e Educacional, 9(2), 303-312.

Rodrigues, S. (2010). Círculos de debate e sua contribuição para o ensino de alunos com dificuldade de aprendizagem. Psicologia da educação, 30, 147-159.

Silveira, L. M. O. B., \& Wagner, A. (2012). A interação família-escola diante dos problemas de comportamento da criança: estudos de caso. Psicologia da educação, 35, 95-119.

Watzlawick, P., Beavin, J. H., \& Jackson, D. D. (2007). Pragmática da comunicação humana: um estudo dos padrões, patologias e paradoxos da interação. São Paulo: Cultrix.

Recebido em: 29/05/2014

Reformulado em: 08/06/2015

Aprovado em: 06/07/2015

\section{Sobre as autoras}

Tarcila Barboza Hidalgo Lima (tarcilabarboza@live.com)

Psicóloga pela Universidade Federal do Triângulo Mineiro (UFTM). Residente em Saúde da Família, na Pontifícia Universidade Católica de São Paulo (PUC-SP), campus Sorocaba.

Cibele Alves Chapadeiro (cibelechapadeiro@psicologia.uftm.edu.br)

Psicóloga, professora adjunta do curso de Psicologia da Universidade Federal do Triângulo Mineiro (UFTM). Doutora em Psicologia pela Universidade de São Paulo (USP). 